HISTORICO DA ESCOLA DE ENFERMAGEM

DA UNIVERSIDADE DE SAO PAULO

Maria Rosa Sousa Pinheiro*

Fase Preparatória

A Escola de Enfermagem da Universidade de São Paulo nasceu do interêsse da Fundaçāo Rockefeller em cooperar na defesa de saúde dos povos da América Latina. Quan do esta Fundação,em 1925, em convênio com o Govêrno do Es tado, contribuiu financeiramente para a construção e o equipa men to da Faculdade de Medicina da Universidade de São Paulo, fê-10 sob várias condiçōes, uma das quals seria a criação de uma escola de enfermagem. A Fundaçāo kuckefeller, em 1923, a pedido de Carlos Chagas, já havia dado contribuiçāo definiti va à críaçāo da Escola de Enfermeiras Ana Neri, no Rio de Janeiro, subordinada à Superintendência do Serviço de Enfer meiras do Departamento Nacional de Saúde Pública, DNSP.

Os anos decorreram. O nôvo prédio da Fa culdade de Medicina e 08 seus laboratórios haviam-se tornado motivo de orgulho para sāo Paulo, m as a escola para a forma çäo de enfermeiras permanecia no limbo.

Em 1939, o grupo de médicos que fundara a Escola Paulista de Medicina conseguiu, com a cooperaçāo da Ordem das Francícanas Missionárias de Marla, a criação da Escola de Enfermeiras do Hospital Sāo Paulo; já anteriormente outros cursos de enfermagem funcionavam em Säo Paulo, inclu sive o da Cruz Vermelha, mas o Govêrno Estadaal mantinhase alheio a este movimento.

Em maio de 1940 a chefe de Seç̧ão de Enfer magem da Fundação Rockefeller, Miss Mary Elisabeth Tennant,

* Diretora da Escola de Enfermagem da Universidade de Säo Paulo. 
veio a Sāo Paulo avivar a memória dos responsáveis pelo acôr do com aquela Fundação. Acompanhava-a como intérprete a en fermeira e nutricionista Yolanda Lindenberg, que posteriormen te lecionou Nutrição e Dietética na Escola de Enfermagem.

A vinda de Miss Tennant ao Brasil precipitou os acontecimentos. Em reuniōes no Palácio Campos Elíseos, com o Dr. Adhemar de Barros, entāo Interventor Federal em Sāo Paulo, e na Faculdade de Higiene e Saúde Públlca da Uni versidade de Sīo Paulo, entāo Inst tuto de Figiene da Faculdade de Medicina, com seu Diretor, o Professor Geraldo de Paula Souza, foram discutidos os planos da futura escola e quais as contribuiçōes do Govêrno do Estado e da Fundaçāo Rockefeller.

Ficou desde logo assentado que a Escola de Enfermagem seria criada na Uníversidade de Sāo Paulo, anexa à Faculda de de Medicina. Fol a segunda escola de enfermagem brasileire a fazer parte de uma universidade, pois a Escola Ana Neri havia sido transferida, em 1937, do Departamento Na cloanl de Saúde Priblica para a Universidade do Brasil, como instituiçāo complementar *

A pedido de Miss Tennant fôra feito um le vantamento que revelara a nāo existência em Sāo Paulo de en fermeiras disponíveis para a direçāo e a docência; fol pois re solvido que seriam convidadas enfermeires de outros estados enquanto era preparado pessoal local.

Para a direçāo da tutura escola fol convida da a enfermelra Edith de Magalhäes Fraenkel, ex-superinten dente do Serviço de Enformeiras do DNSP, que acabava de ser extinto. Sua larga experiência de ensino e de administraçāo e seu temperamento indiscutível de líder eram credenciais para - êxito de suas novas funçōes.

* Em 1946 passon a Escola Ana Neri à categoria de estabeleci mento de easino superior. 
Para a docência ficou decidido que seriam preparadas em universidade do exterior seis educadoras sani tárias de São Paulo.

O Govêrno do Estado, por beus órgãos com petentes, comprometia-se a contratar a enfermeira diretora e auriliares para fazerem o plano da futura escola; a selecionar as sels educadoras que deveriam ser preparadas para a docến cia nos anos futuros à sua instalação e manutençāo; finalmente, a fechar o curso de educadoras sanitárias do Instituto de Higie ne, quando a essola de enfermagem fôsse iniciada, curso êsse que funcionava desde 1824 e cujas diplomadas estavam sendo a proveitadas pela Secretar de Saúde para exercerem as fun çōes de enfermagem de saúde públice.

A Fundação Rockefeller por sua parte com prometin-se ao seguinte :

1. conceder bolsas de estudo para a Sra. Edith de Ma galhäes Fraenkel fazer estágio de observaçāo em escolas de en fermagem de universidades americanas e canadenses;

2. conceder bolsa de estudos às seis educadoras sani tárias selecionadas pare fazerem o curso de enfermagem no ex terior;

3. doar a importância de U.S. \$\$0.000,00: para a monta gem da biblioteca dos laboratórios da Escola.

De agôsto de 1940 a julbo de 1941 a senhora Fraenkel estagiou em escolas de enfermagem de universidades americanas e canadenses; cm setembro de 1940 geguíram para - Canadá a fim de fazer o curso de enfermagem na Universida de de Toronto, Zllda A.Carvalho e Maria Rosa S.PInheiro e em agôsto do ano seguinte Glete de Alcântara e Lúcia Jardim. As duas primeiras voltaram ao Brasll em fins de 1943 e as últi mas em fins de 1944, após terem completado os cursos de en fermagem geral e enfermagem de saúde pública. Mais dua edu cadoras sanitárias, já selecionadas, deveriam seguir para To ronto em agôsto de 1942 , mas as suas bolsas de estudo foram suspensas em virtude da entrada dos Estados Unidos na 2a.Guer re Mundial. 
Em outubro de 1941 chegou a São Paulo a Sra. Fraenkel, que iniciou a elaboração do Regulamento da fú tura escola e 08 entendimentos com as autoridades sobre a sua instalaçāo.

Nessa altura eram também preparados 08 planos do Hospital das Clínicas. De acôrdo com o Regulamento dêste a Diretora da Escola de Enfermagem era orientadora da Sub-Divisāo de Enfermagem do Hospital. Nesta qualidade a Sra. Fraenkel liderou o preparo de material para aquela SubDivisāo, inclusive escreveu, com a cooperagño de enfermei ras contratadas para trabalharem no futuro hospital, tôdas as técnicas a serem usadas pelo pessoal de enfermagem.

Em 31 de outubro de 1942 era assinado pelo Interventor Federal Fernando Costa o Decreto-Lei ne 13.040 que criava a Escola de Enfermagem de Sāo Paulo, anexa à Fą culdade de Medicina da Universidade de São Paulo com as se guintes finalidades :

a. preparar enfermeiros técnicos para 08 serviços de saúde pública e hospitalar;

b. habultar enfermeiros diplomados por escolas es trangelras, reconhecidas pelas leis de seus países.

Embora anera teve a Escola desde seu início relativa liberdade de açāo, concedida pelo próprio decreto que a criou que rezava: "para efeito de administração interna, a Es cola é organizada e considerada como divisāo autônoma, dentro da jurisdiçāo geral da Faculdade de Medicina" (Art.19, Paré grafo Unico).

Os estágios dos estudantes seriam obrigató riamente "no Hospital das Cĺnicas e no distrito sanitério do Instituto de Higiene".

A administraçāo superior era exercidı por um Conselho Administrativo constituído de 4 membros natos : Diretor da Faculdade de Medicins., Presidente, Diretora da BB cola de Enfermagem, Secretéria, Diretor do Instituto de Higie ne e Superintendente do Hospital das Cĺlnicas e dois membros 
eleitos, un professor da Faculdade de Medicina indicado pelo seu Consel ho Técnico Administrativo e uma professôra da EB cola de Enfermagem, eleita por seus pares.

A criaçāo ja Escola de Enfermagem näo foi acompanhada da criaçāo de quadro de docentes : 0 Decreto-Lei apenas mencionou que 0 corpo docente seria constituído por en fermeiras diplomadas, contratadas pelo Govêrno e por profes sôres ou assistentes da Universidade de São Paulo que percebe riam, a título de gratificação, a importância de $30 \$ 000$ por aula (!). Foi criado, isso sim, um quadro administrativo, constituí do de dois cargos, um de diretor e um de assistente de ensino, que mais tarde transformou-se em "vice-diretor", o demais pessoal necessário seria extranumerário.

Em 13 de outubro de 1943, dois anos após a sua chegada em São Paulo, a Sra. Fraenkel pronunciava a aula Inaugural da Escola de Enfermagem, numa das salas do Hospi tal das Clínicas, ainda nāo inaugurado, que seria a sua sede a té o término do prédio próprio, cuja construçāo já havia sido iniciada em terreno da Faculdade de Medicina, ao lado do HoE pital.

Edifício e Instalaçōes

O belo edifício onde funciona a Escola de En fermagem, que lembra um navio, e foi denominado pelos estu dantes de medicina, na época de sua inauguração, de "Montene gro Maru", fol doado à Universidade de São Paulo pelo entāo Serviço Especial de Saúde Pública (SESP), hoje Fundaçāo SESP.

Era êste um serviço de cooperaçāo entre os govêrnos do Brasil e dos Estados Unidos, nascido em 1942 jun to ao Ministério da Educação e Saúde,em virtude da necessidade de proteção à saúde dos que trabaihavam em áreas de interêsse vital para a indústria de guerra: a borracha da Amazónia e 
- minério do Rio Doce. Posteriormente o SESP estendeu - se pràticamente por todo o País. No seu inf́cio foi mantido quase exclusivamente com verba americana; aos poucos foi aumentan do a contribuição do Brasil e diminuindo a dos Estados Unidos, até que êste último retirou-se do quadro. Hoje a Fundaçāo SESP é nma organização inteiramente brasileira.

O SESP funcionou inicialmente com consul tores e técnicos americanos, inclusive enfermeiras; mas estas nāo eram suficientes para suas atividades em expansāo. Fôsse aquêle um Serviço brasileiro, provàvelmente teria funcionado com "enfermeiros" improvisados, como acontecia e ainda a contece na major parte do Paĺs; mas 08 americanos não aceita vam esta hipótese. Para ter em seus serviços enfermeiras di plomadas, o SESP recrutava jovens nas áreas onde atuava e as encaminha ra a escolas de enfermagem, com bôlsas de estu do; por outro lado, auxiliava as esculas com maior probabill dade de desenvol rimento.

Várlas universidades braslleiras estavam em vias de criar sua escola de enfermagem e o SESP decidiu construir o prédio de uma delas. Graças ao Dr. Bernardo Mc D. Krug,que na ocasiāo era Superintendente em exercício da quele Serviço, a escolha recaiu sôbre a escola da Universidade de São Paulo.

Fol constituída uma comissāo integrada por membros do SESP, da Escola e da firma construtora e presidi da pelo Professor Benedito Montenegro, Diretor da Faculdade de Medicina, para coordenar as atívidades de construção do prédio.

Um arquiteto americano do SESP, Peter Pfisterer, fêz o plano da Escola, cuja maquete ganhou mais tarde um prêmio em Boston. A obra fol entregue à firma Lin denberg e Assunçāo, hoje extinta, e sua fiscalizaçāo a um engenheiro americano, Oscar Lokofaki, da equipe técnica do SESP. 
em 8 mil contos, 4 mil para a conatruģão do prédio e 4 mil pa ra a sua instalegẽo. De acôrdo com coavênio firmado entre o SESP e o Govêrno do Estado, a contribuiçāo seria de 50\% pa ra cada ume das pertes. O SESP, que nessa ocasiño funclonava como verba americana, doou U.S. $\$ 200.000,00 ; 00$ câmbio de 20\$000, devertam ser auficientes para cobrir a sua parte que seria a construçēo do prédio, fleando para o Govêrno do Esstado a instalação.

A construgāo teve infeio em setembro de 1943. O aumento do custo de material e mäo de obra, que na quela ocastīo começon a fazer-se sentir, obrigou ambas as par tes do convênio a suplementarem a importêncla inicial,para que - prédio não ficasse inacabado.

A duras penas foi êste terminado, is pres sas, antes que os preços subissem alnda mais. A cobertura do edtfício nāo correspondeu is suas fundaçōes; o subsolo fôra constrúdo de modo a servir de abrigo anti-aéreo - é preciso lembrar que 0 s bombardetos na Buropa eram dírios o bom be atómica ere ainda desconhecida - mas a lage de cobertú ra fol tão mel acabada que três anos após a inauguraçäo do pré dio, a fnflitraço de águas pluviais já era um problema terrí vel, com o qual lutamos até hoje.

A mudança para o nôvo prédio era esperada com analedade tanto por parte da Eacola como do Hospital. Inau gurado em abril de 1944 o Hospital das Clínieas já abrigava, em 1947, a maioria dos serviços tracuferidos da Santa Casa, was a Eacola coupara a área de trés clínicas que oó esperavam a sun saída para se instalarem no nôvo Hospital. Além diseo a viva cidade de cem jovens, aaturalmente ruidosas, prejudicava o sossề dos doentes e causava atritos inevitáveis eatre a dire çio dos dols entabelecimentos.

Finalmente, em 31 de outubro de 1947, qua tro anos após o seu iríclo, fol limugurado o prédio da Escola de Bufermagem. 
A sac entreda uma placa comemorativa traz

os seguintes dizeres :

M.E.S.

SERVIÇO ESPECLAL DE SAODE PÚBLICA

ESTA ESCOLA DE ENFERMAGEM, SMBBOLO DE UMA SA POLITICA DE BOA VIZINHAÇA, FOI CONSTRUIDA PELOS GOVERNOS DOS ESTADOS UNIDOS DO BRASIL E DOS ESTADOS UNIDOS DA AMERICA, COM A COOPERAÇÃO DO GOVÊRNO DO ESTADO DE SÃO PAULO.

O arquiteto, ao planejar o edifício da escola, valeu-se de sua experiência sobre as escolas de enfermagem a mericanas, em sua maioria localizadas junio a um hospital,que com elas reparte suas instalaçōes. O plano da escola de são Paulo compreendendo uma parte destinada ao ensino e outra à administraçāo e à residência, previu apenas uma sala de au las; nāo previu laboratório de dietética, escritórios para pro fessôras, cozinha e lavanderia, na suposição de que seriam usados 08 recursos do Hospital das Clínicas.

Desde logo verificou-ge que a suposição ha via sido quimérica e que o Hospital nāo poderia dar à Escola o auxílio esperado; a sua lavanderia era de tamanho insuficiente para a lavagem da própria roupa; a cozinha näo teria capacida de para preparar refelçōes de mis uma instituição; as salas de sulas, cada uma de um professor catedrático, nem sempre estavam disponíveis; näo havia, no hospital, salas para as pro fessôras da Escola.

Com o tempo foram séndo feitas adaptaçōes: cozinha e lavanderia foram construldas, aquela so lado da $\infty$ pa, esta no poräo; 14 quartos de primeiro andar, que haviam sido planejados para três pessoss, foram tranformados era pe quenas salas de aula, ala do Serviço de Saúde, sede do Centro Acadêmico e escritórios de professôras; a cada ano que passa mais alguns dos 140 quartos individuals existentes estīo sendo 
transforiandos em escritórios. O laboratório de Anatomia fol transformados em sala de aula pols as zulas práticas dessa dis plina eram realizadas na Faculdade de Medicina; hoje, que já nảo há a mesma ligaçāo entre as duas instituiçōes, a Escola ressente-se profundamente dessa falta. A área destinada a re feitório do corpon docente fol adaptada pira Laboratório de Die tética; no porāo, que na face sul é o rés-do-chāo, foram cons truídos 4 quartos e sanitários para alunos do sexo masculino.

Com o desenvolvimento de Brcola e o aumen to do número de cursos, as dependências tornaram-se insufí cientes; a biblioteca fol dupliceda e há projeto de construção de salas de aula quando houver recursos.

Apesar de suas atuals deficiências o prédio da Escola é cômodo, estético e funcional. O "Montenegro Maru " tem preenchido galhardamente as suas finalidades e por estra nho que pareça, com pouquíssimo acréscimo de área, tem com portado as atividades da escola, atividades estas quasi decupli cadas nestes 25 anos.

Funcionamento

A primeira turma, admitide em 13 de outu bro de 1943, compunha-se de 35 candidatas, quasi tôdas profes sôras primárias comissionadas pelo Govêrno do Estado. For maram-se 17. Näo havia exame vestibular, o que explica, em parte, esta altíssima taxa de evasāo: mas ainda hoje, que há a quele exame, é elevado o número das que abandonam o curso a meio caminho; muitas jovens nāo estāo preparadas para a serie dade de propósitos, a intensidade do ritmo de estudos e a die ciplina que encontram aas escolas de enfermagem.

Cíco meses após a instalação do curso, em março de 1944, era adinitida a segunda turma, com 41 estudan tes, das quals 28 bolsistas do SESP, de estados do norte, centro e sul; nesta a evasão fol menor : formaram-se 37 . 
En março de 1943 inicion-mo o ano excolar cem as professôres primárias, pois o comissionamento atra sara. Eate só fol publicado em fins de malo, o que obrigou a eecole a iniciar nova turma em 19 de julho.

A prática de receber duas turmas por ano ere muito comum ase escolas de enfermagem do Brasil e do es trangeiro, mas eata Eacola año se propunha a adotar tal políf ca. Em tôda a sua histórín foi a única vez que o fêz, com gran de sacrifficio para 0 corpo docente privativo, na época muito re duzido.

Mais tarde o Govêrno do Estado abandonou a polftica de comissionar professôras primérins para estudos em outras escolas, menos que o Regulamento destas assim o de terminasse. Como nada houvese no Regulamento da Escola de Enfermagem nesse sentido, näo mais foram comissionadas profensôras para fazerem o curso de enfermagem, salvo rarís simas exceçōes.

As turmas toranam-se menores desde que as professôras delxaram de ser comissionadas e O SESP pas sou a enviar suas bolsiotas para as escolas de enfermagem que vinham sendo criadas nos estados onde equềles Serviço recru tava as candidatas.

O primeiro Regulamento da Escola, baixado em 1846 por Decreto Lei *, segula de perto os dispositivos do Decreto Lel de sua crinģāo.

Inm 1946 fol a Escola equiparada ì Escola Ana Neri ** Em 1949 fol promulgada a primetra lel federal re gulando o ensino de enfermagem, Lei ni 775, de 6 de agôsto de 1945, que transformou as escolas equiparadas em reconhe cidae.

- Decreto Lel ne 16.308 de 16 de novembro de 1946.

* Decreto Federal di 21.965 de 21 de outubro de 1946. 
O processo de adaptação do Regulamento da Escola e esta lei foi demorado; só em 1954 foi aprovado o nôvo Regulamento, baixado por decreto estadual * .

A Lei $775 / 49$, no seu período de vigéncis até a promulgação da Lei de Dịretrizes e Bases da Educaçāo Nacio nal, teve grande repercussāo. Como determinasse a criaçäo de escolas de enfermagem em tôdas as universidades e centros médicos, e auxîlio federal a tôdas, abriram-se escolas univer sitárias ou isoladas em todo o Paĺs; na cidade de São Paulo che gou a haver sels. A da Universidade de São Paulo durante ês se perfodo criou cursos de auxiliar de enfermagem, superior de enfermagem e de pós-graduação, sem deirar de realizar o cur so normal com o qual havia iniciado suas atividades.

Desde 1944 latou a Escola pela criaçāo de qua dro: de pessoal docente e administrativo, sem êxito algum; nesse sentido chegou a haver projeto de lei no Govêrno Lucas Garcez, mas foi retirado da Assembléia Legislativa no Govêrno Jânio Quadros, por medida de economia. A Escola de Enfermagem de Ribeirão Prêto, também da Universidade de São Paulo, cria da 11 anos depois da de São Paulo, teve seu quadro aprovado em 1960. E precioso lembrar que ambas as escolas eram anexas a Faculdade de Medicina cujos diretores as representavam no Conselho Universitário**.

Em dezembro de 1963, dois anos após a pro mulgaçēo da Lel de Diretrizes e Bases e 21 anos após a sua cri açāo, ere a Escola de Enfermagem de Säo Paulo desanexada da Faculdade de Medicina e transformada em estabelecimento de ensino superior ***.

* Decreto a9 23.796 C de 10 de novembro de 1954.

* Em 1867 foram criados alguns cargos de Chefia (Decreto n? 47.818 de 9 de março de 1967), os únicos cargos admi nistrativos possíveis dentro da atual estrutura do funciona lismo civil de Sao Paulo.

*** Decreto $n 942.809$ de 20 de dezembro de 1963 . 
O Regulemento de 1956, já agora caduco por força do nôvo Estatuto da Universidade de São Paulo e da pró pria estrutura da Escola, deverá ser substituído. No momento em que escrevemos êste histórico o projeto do nóvo Regulamen to encontra-se na Consultoria Jurfdica desta Universidade, an tes de ser encaminhado ao Conselho Universitário para aprova ção. Acompanha-o projeto de quadro de docentes criando 15 cargos de professor catedrático e 28 de instrutor.

Como a Escola de Enfermagem nāo conta ainda com Congregaçāo e Conselho Departaureatal * Conse tho Universitário faz as vêzes da Congregaçäo e um Conse Iho Técnico Administrativo atua como Conselho Departamental. O C.T.A. é composto da Diretora da Escola de Enfermagem, que 0 preside, mais quatro membros do Conetiho Universitá rio, dos quais um é aluno.

A díreçāo da Escola é exercida por uma Di retora efetiva, como determinou o Decreto-Lei de sua criaçāo, cargo êsse que ao vagar será extinto.

Uma "Comissāo de Ligaçāo", constituída de duas representantes da Escola e uma de cada hospital do Cen tro Médico onde estagiam as estudantes e do Centro de Aprendi zado Urbano da Faculdade de Higiene e Saúde Pública da U.S.P, estudam os problemas surgidos no estágio das estudantes e cin co comissōes permanentes, compostas quasi exclusivamente de membros do corpo docente priyativo, cooperam na direçāo, au xiliando a Diretora em caráter consultivo; sāo as comissōes de Coordenação e Planejamento, Assistência ao Aluno, Biblioteca e Publicaçōes, Ensino, Relaçōes Públicas. O trabalho das Co missóes é precioso, tanto para a integração do corpo docente nes atividades da Escola como para facilitar o trabalho da DI retora, que assim se beneficia da opiniāo de um grupo ao invés de depender exclusivamente de seu próprio julgamento.

* Na Universidade de São Paulo a Congregação e o Çonselho De partamental só podem ser instalados quando um terço das că tedras da Escola estiverem preenchidas em caráter efetivo. 
Sòmente depois de extinçāo do cargo da Dire tora, da aprovaçāo do nôvo Regulamento e da criaçāo do quadró de docentes terá a Escola de Enfermagem estrutura idêntica à dos demais estabelecimentos de ensino superior da Universida de de são Paulo.

\section{Corpo Docente}

Desde o iń́cio das atividades da Escola têm participado do ensino dois tipos de docentes : as professôras e instrutoras privativas, enfermeiras contratadas por determina do espaço de tempo, que lecionam os diversos ramos da enfer magem e fazem supervisāo do estágio dos estudantes e os pró fessôres nāo privativos, que recebem gratificaçāo por aula mi ni strada, segundo o disposto no Decreto Lei de sua criaçāo.

As disciplinas básicas eram lecionadas por assistentes da Faculdade de Medicina, as de saúde pública por assistentes do Instituto de Higiene e as ciências humanas e so ciais por assistentes da Faculdade de Filosofia Ciências e Le tras.

Em 1943 trabalhavam na Escola as enferme1 ras Haydée Guanais Dourado, Zélin Carvalho e Clarice Ferrarini, esta íltima posta à disposição da Escola pelo Hospital das Clíni cas, que ainda não estava em funcionamento. Aberto o Hospital, em 1944, a Sra. Ferrarini voltou ao seu posto como enfermeira chefe e em 1945 passou a chetiar a Sub-Divisão de Enfermagem daquele Hospital, cargo que ocupa até hoje como Diretora daque 1a Sub-Divisão. Em 1958 entrou em vigor o nôvo Regulamento do Hospital das Clínicas que excluiu o item referente à Sub-Divi são de Enfermagem ser orientada pela Diretora da Escola de Enfermagem; aliás esta orientaçāo na realidade já não venha sendo feita desde 1945.

A separação dêstes dois cargos, de Diretora da Escola de Enfermagem e Diretora da Sub-Divisäo de Enfer magem do Hospital, se por um la do apresenta vantagens, por ou tro: pode pôr em risco o aproveitamento dos estudantes na parte 
maí importante do currículo, que é o estágio prático; para que ésse risco nāo ocorra é preciso que haja a mais estreita coope rağio entre as asus ocupantes. Clarice Ferrarini, no decor rer de todos êstes anos, tem sido grande amiga da Escola e tem dado o máximo apôio aos estudantes estagiários e às docen tes que 08 supervisionam.

Das quatro bolsistas da Fundação Rockefeller enviadas ao Canadá três, à sua volta, passaram a trabalhar na Escola; a quarta fol retita pelo Professor Paulo Souza no Inatituto de Higiene, alegando êste que, so chefinr a enferma gem no centro de saúde do Instituto, ela poderia colaborar no ensino de saúde pública dos estudantes quando estaglassem na quele centro. De fato, até sua morte Lúcia Jardim nunca dei zou de participar ativamente do ensino dêsses alusos.

De tôdas as enfermeiras que lecionaram na Escole em seu período inicial permanecem apenas a sua atual diretora e a professôra Ruth Borges Teixeira. A exceçāo deg tas duas, de uma nutricionista e de três instrutoras, o corpo do cente privativo, atualmente de 13 professóras e 22 instrutoras, é composto de diplomadas da própria Escola.

\section{Curso de Graduaçāo}

Requisitos de admissäo

Ao ser criada a Escola foi determinada, co mo requisito de admissāo, apresentaçāo de diploma de curso ginasial. Era esta uma novidade no Brasil pois o Decreto Fe deral que regulava o funcionamento da Escola Ana Neri ${ }^{*}$ esti pulara a exigéncia de diploma de normal para a matrícula, mas deixara uma porta aberta para candidatas que não possuíssem 
tal diploma, desde que comprovassem. "ter instruçāo secundá ria bastante" ou fossem aprovados em exame vestibular na pró pria escola. Tendo a legislação federal determinado que a Es cola Ana Nerl serta "padrāo", à qual as demais deveriam ser quiparadas * generaliou-se a nāo obrigatóriedade da apresen tação de um diploma para matrícula. A Escola de Enfermagem da Universidade de Säo Paulo fol a primeira a fazer tal exigên cis.

A Lel Federal $775 / 49$ determinou, como re quisito de admissāo, curso secundárto completo, com prazo de 7 anos para ser posto em vigor, podendo as escolas, duran te êsse perf́odo, receber candidatos com curso ginasial, normal ou comercial. No inf́cio de 1956 estava em ebulição o grupo de educadores de enfermagem. Esgotara-se em 6 de agôsto o prâ 20 para admissāo de candidatos com ginásio. Um inquérito fel to em 1954 pela Associaçāo Brasileira de Enfermagem entre di retores, professôres e alunos de escolas de enfermagem revé lara que 08 dois últimos grupos eram francamente favoráveis à exigência de curso colegial ou equivalente e que apenas as dire toras estavam divididas; havia receio, por parte de um grupo, príncipalmente das que eram responsávels por hospltals mant1 dos pelo trabalbo das alunas, de que a matrícula, já pequena, caĺsse atnda mais. Não atentava êste grupo na experiência an terior, de quando houvera a exigência de ginásio; naquela oca siāo a matrícula caíra durante 2 anos para depols ultrapassar as cifras anteriores.

O deputado federal por São Paulo, Dr.Lauro Cruz, eutor de substitutivo que mais tarde se tornara a Lei no $775 / 49$, no intuito de conclliar o desejo dos dois grupos apresen tou projeto de lei que permitia, durante um certo número de anos, a coexistência de cursos de enfermagem de dois níveis, 
colegial - superior, respectivamente de 3 e 4 anos; mas êste projeto fol prejudicado por outro, do Senado, que adiava por cinco anos a obrigatoriedade do secundário completo para ad missão. Convém notar que êste último foi da autoria do Sena dor Vivaldo Lima, Diretor da Cruz Vermelha Brasileira, que mantinha no Rín de Janeiro uma escola de enfermagem e um hospital. Este projeto passou pelas Casas do Congresso co mo um bólido e em 10 de dezembro de 1956 tornava-se lei ${ }^{*}$.

A vista da nove lei, Escole de Enfermagem da Universidade de Séo Paulo, que já havia publicadu editais com a exigência de secundário completo, voltou atrás e conti nuou a admitir candidatos com curso ginasial. Havendo entre tanto a direção verificado que um têrço dos candidatos à matrí cula traziam certificado de curso colegial ou equivalente, plei teou junto ao Conselho Administrativo da Escola o direito de ini clar o curso superior; só obteve essa permissão com a condi çāo de não suspender o curso normal. A autorização do Conse Iho Universitário não chegou em tempo de permitir que o nôvo curso fôsse iniciado em 1957, como desejava a escola de São Paulo e como fêz a da Universidade da Bahia; a instalação do curso superior só se deu em 1958. NOs anos que se seguiram, as escolas de Ribeirāo Prêto, Pôrto Alegre, Recife, Ana Neri e Escola de Enfermeiras do Hospital Sāo Paulo fizeram o mes mo. Quando, em agôsto de 1961, expirou o prazo para admí sāo com ginásio, nāo renovado devido à oposiçāo de enfermế ras de norte e sul do País, sete escolas de enfermagem já rea lizavam cursos superior. A hesitaçāo anterior a 1956 havia de saparecido; desta vez as diretoras juntaram suas fôrças às das docentes e, com a Associaçāo Braslleira de Enfermagem , conseguiram impedir o andamento de um nôvo projeto de lei que adiava por mais cínco anos o prazo fatal.

Em 1958 abria pois a Escola matrícula para dois cursos diferentes : normal e superior. Fol a única escola 
do País a fazer tal experiência. O curso normal manteve-se ain da por mais 4 anos quando, esgotado o prazo, foi posta em execu f̧āo a exigência legal de secundário completo para admissão.

\section{Duraçào}

A duraçāo do curso fol inicialmente de 3 a nos calendáríos de 11 meses, equivalentes 24 anos académicos, de acốrdo com a escola padräo.

A Lei Federal nq 775/49 estipulou em 36 meses a duraçāo do curso. Qaundo entrou em vigor o segundo Regulamen to da Escola, de 1954, c.japtado às disposiçōes daquela Lei, os 36 meses foram distribuídos em 4 anos como jả vinham fazendo as escolas de Pôrto Alegre, Bahlo, Recife e Rihọía Prêto. As férias passaram a ser de 4 semanas no inverno e 8 no verão. Como se vê, apesar de já se aproximar muito mais dos cursos secun dários e superiores, ainda assim o seu ano acadêmico, de 40 se manas, que até hoje continua, era mais longo que o habitual. A turma de 1956 já se formou em 4 anos.

No regime de coexistência dos cursos nor mal e superior, o primeiro fol planejado para trés anos e o segundo para quatro, de acôrdo com o projeto de lei do deputado Laurc Cruz. Como entretanto o projeto nāo tivesse sido leva do avante, ao fim do 39 ano, ou seja, de 27 meses de curso, não fol possível diplomar os estudantes do curso normal, de vez que a lei em vigor estipulava 36 meses. Pôde então a Escola pôr em execuçāo um plano que há muito desejava tentar: o de possibilitar aOs estudantes fazerem "internato" : no Hospital das Clínicas, mediante pequena remuneraçāo, como acontece com os estudantes de medicina; o resultado fol excelente; o mesmo se deu com a turma seguinte, mas já em 1963 não tive ram mais as alunas essas oportunidade, pois diplomavam-se ao fim do 39 ano, em obediência a disposição do Conselho Fe deral de Educaçāo que, em 1962, ao determinar a duração e 0 currículo mínimo do curso de Enfermagem, reduziu-o para 3 anos (Parecer ne 271/62). 
Tôdas as escolas do Brasil, mesmo as que já distribulam os 36 meses em 4 anos, passaram a ministrar 0 curso em 3 anos.

O resultado foi mau. E possível comprimir -se a parte teórica de um currículo ministrando-se menor nú mero de eulas ou submetendo-se os alunos a uma jornada diá ria mais longa, mas o mesmo näo se dá com a parte prática; o amadurecim ento dos estudantes, processado durante os está gios práticos, nāo pode ser acelerado além de um certo limite, a não ser no caso de estudantes excepcionais. Eerdade que os Estados Unidos, o Canedá e alguns países da Buropa estāo formando enfermeiras com 2 anos de curso (24 meses), mas es tas, quando se formam, väo prestar cuidados diretos 208 paci entes, em hospitais onde hí enfermeiras chefes nara orientalas e programas organizados de "educaçāo em serviço"; o mes mo não se pode dizer das nossas diplomadas, cuja maioria de iń́cio já se empregam em posiçōes de responsabilidade, às quais nāo é dada orientação alguma; so contrário, delas se es pera que orientem o pessoal auxlliar.

A experiência das demais escolas é a mes ma. Já no Congresso de Enfermagem de 1963, e em todos os congressos posteriores, o assunto tem sido debatido. Vários pedidos têm sido dirigídos pela Associnção Brasileira de Enfer magem $\ni 0$ Conselho Federal de Educaçāo, para que reconside re o Parecer n̊ 271/62, mas êstes pedidos nāo têm encontrâ do éco. Alegam os senhores conselheiros que as enfermeiras desejam ampliar o curso de 3 para 4 anos a fim de usufruir os benefícios que a legislaçāo federal concede aos cursos desta du reçāo. Acontece que desde 1965 o curso de enfermagem foi classificado como de 4 anos * es enfermeiras já usufruem tals beneff́cios, mas as escolas continuam a pleitear a volta ao curso de 4 ano $B$.

* Decreto Federal a9 57.180, de 8 de novembro de 1965. 
Desesperançadas de conseguir algo do lado do Conselbo Federal de Educaçāo as duas escolas de enferma gem da Universidade de Sāo Paulo trataram de resolver o seu problema; indagando da Consaltoria Jurfdica da Universidade de Sāo Paulo se haveria possibilidade de prolongarem o curso para 4 anos, foi-lbes respondido que o item el do artigo 89 da Lei de Diretrizes e Bases, sobre a competência do Conselho Fe deral de Educaçäo em "estabelecer a duraçāo e o curríleulo mí nimo dos cursos de ensino superior ... " é por equele Consulto rin interpretada como durecēo minima corrículo mínimo e que portanto as escolas näo precisaräo cingir-se ao mínimo. Esta intexpretaçio do texto de lel permittu que ambas as esco las pletteassem e obtivessem Portaria do Magaffico Reitor * com permissão para realizarem o curso de graduação em 4 a nos.

Curriculo

A princípio fol seguldo de perto o currículo da escola peidräo.

O Regulumento da Lel Federal ne 775/49 ** näo alterou grandemente o programa anterior; Incluin as ciên clas biesicas de todos os cursos chamados blológicos, clências sociais, clências humanas e 08 diferentes ramos da enfermagem; nào determinou a duraçio dos estígios que acompanham estas últimes disciplinas, exceto 0 de enfermagem de sańde pública que deveria ser de três meses.

- currículo da Escola de Enfermagem da Univeratuda de Sāo Paulo,a princíplo muito prêso ao modê 10 americano, pouco a pouco tomou caracteríticas próprias, adaptadas a situação encontrada no Brasil. Fol esta uma das

* Portaria GR aq 292 de 10 de novembro de 1966 do Reitor da Entrersidade de 8äo Pavio.

* Bairado peto. Decreto Federal ap 27.426 de 14 de novem bro de 1948. 
primelras escoles a inclutr no sen progrema a teorin e a príti ca de administraçāo, com o fim de preparar os enfermeiros pa re as posiçōes de chelia que irlam ocupar logo após o receb1 mento do diplome. Hoje esea disciplina fas parte do currículo minimo.

Outra caracterfistica do curso, allás recomen dada univerwalmente, tem aldo a ênfase dadn à prolllaria das doenças e ì manutenção da saúde. Talves a Bscola tenha sido a primeira do Paf́ em contratar para o seu corpo docente uma enfermeira de saúde pública,exclusivamente para promover a integração no currículo daqueles aspectos da enfermagem.

A atenção dada $\dot{i}$ enfermagem de saúde públi ca no Brasil data de 19.23, quando a Escola Ana Neri foi criada para atender à necessidade que tínha o Fals de enfermelras de saúde pública. Em todos os estados do Brasil, exceto no de São Paulo, estas profisaionais atuam nos ceatros de saúde. Em São Paulo só sāo encontrados nos dols centros de treinamento da Facul dade de Fifífene Saúde Pública (Sño Paulo e Araraquara); nos dẹ mais sāo substituídas por educadoras sanitárias, cujo preparo nāo inclui o estudo das doenças. Foi êsse o motivo pelo qual a Fundaçāo Rockefeller aó auxilizou a criaçāo da Escola de Enfermagem da Uni versidade de São Paulo com a condiçāo de que, aberta esta, fôsse fé chado o curso de educadoras sanitárias do entāo Instituto de Higiene.

O Conselho Federal de Educsção, semi levar em consideraçāo as recomentaçāo dos grupos mais autorizados de educadores de enfermagem de todo o mundo e a tradiçāo bra slleira de 40 anos, no seu desejo de reduzir a duração do curso viu-se forçado a excluir a enfermagem de saúde públice do cur rículo mf́lmo a fazer do seu estudo um cureo de graduaçäo de um ano, uma espécie de 49 ano año obrigatório. E mutto es tranho que um curso de graduaçāo exdje de seus candidatos o diploma de outro curso de graduaç̃o, dispositivo que aliás en tra em conflito com os estatutos das universidades.

Ante os protcstos do Ministério de Saúde, de tôdas as Seç̧ōes da Associaçāo Brasllelra de Enfermagem, das 
escolas de enfermagem, das escolas de saúde pública, o Conse lho Federal de Educaçäo determinou que :

"No curso geral as disciplinas de Enfermagem teräo em viota os aspectos de Saude Pública correspondentes * "

to que tem feito esta Fecola em larga esca la; desde 019 ano os alunos são levados a compreender a inflú encil exercida na saúde pelo melo em que vivem on paciontes, e a importéncia de orientá-los na adoção de hábitos higiênicos; sāo tgualmente ensinados como fazer essa orientaçāo.

Foi esta Escola pioneira numa Iniciativa que já está sesdo seguida em algumas outras: a do exame ao qqual as alunas deram a alcunha de "examāo". Näo existindo no Brasn o "exnme de Estado", tão útıl para a revisāo de conhe cimentos do aluno e como instrumento de auto-avaliaçāo para a própria escolk, fol Idendo uma espécie de exame final do cur so, já inciuf́do no Regulamento de 1856. Consta de três provas: 1) escrita, sôbre todos os ramos da enfermagem, com pergun tas pertinentes aobre qualquer disciplina ministrada no Curso; 2) prática, realieada no Hospital, com o doente ipara esta o alu no sortela na hora uma especialidade da eafermagem; 3) oral, realizada na Escola, sôbre a eapectalidade sorteada na prova prátíse. Ac bancas para as provas escritas e príticas de cada eepecialidade sëo compostas da professôra e uma assistente; a da prova oral inclui ainda a Diretora e um membro da cadeira de Enfermegem de Saáde Pública. A nutricionista participa das bancas de exame oral de três cadelras: Enfermagem Médica, Pe diátrica e em Doenças Transmissíveis. O aluno reprovado em qualquer dxis provas,escrita,prática ou oral, tem oportunidade de $2 a$. época; se fôr reprovado em 2a. época poderá fazer exa mecom a turma seguinte; mas só receberá o diploma após apro vaçāo neote exame. O "examāon é famoso e temido, mas tem dado resultado e grande número de estudantes confessam que a revisano thes tol benéfica.

* Resoluçäo decorrente do Parecer nq 271/62 do Conselho Federal de Fducaçäo. Art. 19 i 29. 
ReBumo

A Escola de Enfermagem da Universidade de São Panlo diplomon, até 1966, 18 turmas do curso normal de enfermagem e, de 1961 até o presente, 6 turmas do curso su perbr.

As turmas adinttidas de 1843 a 1851 fireram carso de 3 anos cilendários equivalentes a 4 anos académicos; de 1852 a 1860; 4 anos; de 1861 a 1966, 3 anos; a partir de 1867 , novameate 4 anos.

Foram conferidos até o presente 498 diplo mes dos queis 419 do curwo normal e 80 do curzo superior. Dos 499 formados 9 sčo do sexo masculino e 480 do feminino.

Cursos de Pós-graduaçáo

Desde muitos anos era centida em todo o País a necessidade da criagão de cursos regulares de pós-gra dusçäo, part o preparo de profeseôras e cheles de enfermagem. Muitas professốras e instrutoras desta e de outras escolas de enfermagem vinham fazendo éstes cursos nos Estedos Unidos ou Canadí, gragas à generosidade de entidades internacionais, Fundaçāo Kellogg. Fundaçāo Rockefeller, Organizaçāo Mundial de Suúde, Govêrno Americano, que lhes concediam bolsas de estudos.

Algumas tentativas já haviam sido feitas pe 1 s eacolas de enfermagem Ane Nerl e Raquel Haddock Lobo, ambas do Rio de Janeiro, que realizaram cursos de pós-gradua çāo de tempo parcial, de dole anos de duraçāo, mas eatas Ini ciativas haviam sido interrompidas.

A chefe de Seç̧āo de Enfermagem da Funda gĩo Kellogg. Miss Mildred Tuttle, em visita ao Brasil, havia dado demonstraçio de que aquela Fundaçāo estaria disposta 
a auxiliar financeiramente a Escola de Enfermagem da Universi dade de São Paulo se esta se dispuzesse a instalar cursos de pós-graduação.

Em 1958, estando já em funcionamento o curso superior, a direçāo e o corpo docente desta Escola acha ram-se em condição de se lançar ao nôvo empreendimento; das 12 enfermeiras com contrato de professôra, tôdas com mais de 10 anos de experiéncia no ensino de suas disciplinas, 9 tínham curso de pós-graduação nos Estados Unidos.

Obtida a anuência da Fundaçāo Kellogg e a autorizaçāo do Conselho Administrativo da Escola foram inicia dos os planos.

Nesta fase contou a Escola com a coopera çāo da Professôra Noemi da Silveira Rudolfer e mais tarde do Professor Florestan Fernandes que opinaram sôbre o currícu 10.

Os planos inictais incluiram dois cursos de um ano acadêmico, de tempo integral, um de "Pedagogia e Di dática aplicada à Enfermagem", para o preparo de professôras de enfermagem e outro de preparo de chefes de unidades de en fermagem hospitalar, de "Administraçāo aplicada à Enfermą gem", tendo os estudantes oportunidade de especializar-se num dos ramos da enfermagem. Para a matrícula seria exigido, a lém do diploma de enfermeiro, um ano de experiência profis sional.

A Fundaçāo Kellogg financiaria as despesas extraordinárias de pessoal e material, acarretadas pelo funclo namento dos cursos, nas seguintes proporçōes : 100\% no primeí ro ano, $75 \%$ no segundo, $50 \%$ no terceiro e $025 \%$ no quarto; a Universidade de São Paulo, a partir do segundo ano, iria paula Inamente tomando a responsabilidade do financiamento até ó quinto ano, quando assumiria a responsabllidade total.

Aceitas as condiçōes pelo Conselho Universi tário da USP e pela Fundação Kellogg foi o convênio posto em execução em 1959. 
A Fundaçāo Kellogg contrlbuiu com U.S. .... $\$ 14.000,00$ em 1959; $10.500,00$ em 1960; $7.000,00$ em 1961 e 3.500,00 em 1962, aum total de US\$35.000,00.

A prova de que êstes cursos correspondiam a uma necessidade do ensino está no fatu de sua procura por en fermeiras de todos os estados do Brasil e de príses de língua portuguésa e espanhola. Ne primeire turma matricularam-se 22 candidatos; embora bouvesse já na ocasiño pedido de outros países, nāo foram êstes atendidos pois pretendíamos fazer a experiência com pessoal "de casa". O êxito dar experiência nos permitiu, já no segundo ano, aceitar alunos estrangeiros. Ês tes são geralmente bol sistas de organizaçāo internacionais co mo Organizaçāo Mundial de Saúde, Organizaçāo dos Estados A mericanos, Fundação Rockefeller ou dos próprios Ministérios ou Serviços do seu país de origem.

Com o decorrer do tempo e por recomenda ção dos própríos alunos foi c requistto de admissāo referente à experiência profissional elevado para dois anos. Posteriormen te mais dois cursos foram iniciados,: "Administração de Ensi no de Enfermagem", para o preparo de diretoras e assitentes de diretoras de escolas e "Administraçāo aplicada a Serviço de Enfermagem" para a form açāo de chefes de Serviço. Outra mo dificaçāo importante foi a possibilidade do aluno fazer curso parcelado, o que tem permitido a multas enfermeiras de são Paulo, matricularem-se no curso sem abandonar seus emprê gos.

A princípio a matrícula só era permitida a enfermeiros, hoje sāo recebidas igualmente as obstetrizes. For maram-se nos cursos de pós-graduaçāo ate o presente, 3 obs tetrizes e 326 enfermeiros; dêstes, 288 do Brasil e 41 de 12 países latino-americano e da Africa.

Iniciaram o curso, em 1967, 87 alunos dos quais 55 em regimen integral e 32 em regimen parcelado. 
O antoprojeto de Reguiamento desta Escola prevê a tranatormação dos cursos de pón-graduagäo em cursos de mestrado, como recomenda o Consel ho Federal de Educaçāo.

Curcer de Enfermagem de Saide Pública e de Ob otetricia

- Conselho Féderal de Edthesço,eo determi nar, em 1982, a duraçāo o o currf́culo mínimo do curso de en fermagem, crion trế cureos de graduacian: un de três anos; de Daferwagem Geral,e dol de um ano - Cbutetricia * En

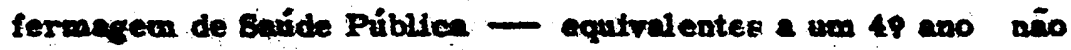
obrigatório.

Ho mesmo ano terminava o convêaio da Uni veraldade de scio Paulo com a Fradagio kellogs para a realisa gấ de curoos de pós-zreduaģio *, ì vista do éxtto dos mesmos, esta Funtagio dispo-se a continuar a prestar auxilio ì escola de Enferwagem.

Fol portanto elaborado plano para a reallza gäo dos dols novos cursos, nas mesmes baces que o anterior, sendo a contribuição da Fundaçäo Kelloges de U\$\$88.000,00 diatr1 buidos em 4 parcelas de $23.810,18.068,10.502$ e 5.622 mais

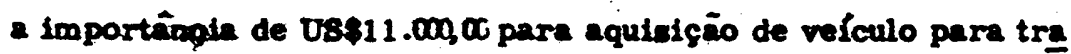
bullo de campo.

Em setembro de 1963 era aprovado o plano, por aquela Fundaço pelo Conpelbo Univeraitirio e em 1064

* Tendo_o Conselho Federal de Irdacaçäo, em 1984, determinado daragéa (s anos) e currículo mínimo de um nôvo curno de Obe tetricia, para candidatos com curso secundir to ou equivaleate. o curso de Obetetrícla, de um ang, para enfermeiras, pascou da categoria de curso de graduaçao para a de "complementa givo" de outro carso. 
Iniciados os cursos que, em 1965, eram aprovados pelo Conse tho Estadual de Fducaçäo* .

Como campo de estágio para obstetrícia foi utilizado o "Amparo Maternal", pois a Clínica Obstétrica do Hospi tal das Clínicas já é insuficiente para os próprios estudantes de medicina e da Escola de Obstetrícia anexa à Facul dade de Medicina.

Os campos de estágio de enfermagem de saú de pública utilizados pela Escola, desde a prim eira turma, fo: ram sempre 08 da Faculdade de Higiene e Saúde Pública da USP, tanto o urbano, em Sāo Paulo, como o rural, em Araraquara . Em 1966, entretento, nāo foram suficientes para o número de alunas do curso e um nôvo campo fol organizado pelas docentes da cadeira de Enfermagem de Saúde Pública no Amparo Ma ternal e nos núcleos fam lliares de pacientes dependentes do Am paro. Para o estágio de Enfermagen de Saúde Pública rural foram também utịizados 08 núcleos de operários da ICOMINAS S.A. EMPRESA DE MINERAÇĀO, localizada no quadrilátero ferriffero de Minas Gerais. Outros serviços tais como ambula tórfos de institutos de previdência, serviços médicos de. indúg trias, postos de assistêncin a tuberculosos estão servindo de campo de estágio para a prática dos estudantes.

O currículo dos dois cursos é pràticamente - mesmo, diferindo apenas na intensidade do ensino e na dura çāo dos estäglos das duas cadeiras principais, Enfermagem Obstétrica e Enfermagem de Saúde Pública.

O Ideal seria a fusāo dos dois cursos num único, de duraçāo mais longa, pois tanto a obtetrí (também de nominada enfermeira obstétrica) precisa de conhecimentos de saúde pública como a enfermeira de saúde pública depende dos conhecimentos de obstetrícia. Mas êste ideal nāo pode ser atín gido no momento, em virtude da legislação vigente e da conventên cla de formar ripidamente as profissionais de que o País ne cesaita em grande número.

* Portaria nq 4/65 do Conselho Estadual de Educação. 
interessante notar o efeito déstes cursos nos estudantes, em têrmos de amadurecimento mental e emocio nal e de modificaçāo do conceito de responsabilidade em pró blemas sociais. Por ésse motivo, de facultativos que eram tor naram-se obrigatórios, pois como fol dito anteriormente o cur so de graduaçāo em enfermagem passon a ser de 4 anos, com opçāo no 49 ano entre Enfermagem de Saúde Pública e Ohatetrí cia: A turma admitida em 1967 já entrou no nôvo regimen. Ao término do 49 ano a estudante receberá dois diplomas : O de en fermeira e o de enfermelra de saide pública ou obstetriz, segun do a opção feita no 49 ano* .

Esta Escola expediu, até 1966, 18 diplomes de Obstetriz e $30^{\circ}$ de Enfermeiro de Saúde Pública ( 1 homem e 28 mulheres).

Curso de Auxiliar de Enfermagem

A Lei 775/49 e sua regulamentaçāo previam a existência do Curso de Auriliar de Enfermagem, de nível mé dio, que contudo nāo se adaptava ao sistema educacional do País, nem em duraçấ nem em requisitos de admissão. Ao in vés de um curso ginasial de enfermagem, que seria equivalente aos chamados cursos básicos comercials, agrícolas ou indus triais, fol previsto um curso de 18 meses, equivalente a 2 anos académicos, ao qual podiam candidatar-se pessoas com primá rio, admissāo a ginásio ou simplesmente aprovados em exame vestibular na própria escola. O referido curso, de currículo elementar, a ser ministrado sòmente por enfermeiras, de 44 ho ras de atividades semanais, era obrigatório em tódas as esco las de enfermagem universitárias.

* Portaria CR n9 292, de 10 de novembro de 1966, do Reitor da Universiade de säo Paulo. 
A Escola de Enfermagem de São Paulo ini ciou o curso de auxiliar de enfermagem em 1954. A princípio, por desejar cooperar aa melhoria do pessonal auxillar do Hospl tal das Clínicas (enfermeiros práticos, práticos de enfermagem ( atendentes) e seguindo o exemplo de outras escoles,organizou horários que permitissem 208 alunos continuar trabalhando. Deatro de algum tempo, entretanto, fol verificado que a sobre carga de aulas, estágios e trabalho, além de afetar a saúde dos alunos prejudiceva o seu readimento escolar. Aliás êste resul tado era de se esperar. Pelo lado da saúde, era realmente pe sado o dia do estudante, de 4 horas diárias de estágio, pela ma nhä, 6 horas de trabalho à tarde, e à noite aulas que, embora elementares, tornavam -se diffeeis para aiunos que há muitos anos haviam deixado os bancos escolares, Pelo lado do aprendi zado a sttuaçāo era ainda mais séria; o pesscal auxiliar de en fermagem que trabalha em hospitais ou ambulatórios, sem pre paro específico, adquire vícios de erradicaçāo dificillima, só conseguida após prática repetida do estudante, em estágios su pervisionados. No sistema por nós adotado o que era aprendi do na teoria e praticado sob supervisāo no estágio era destrú do nas horas de trabalho de rotina sem supervisāo. Outras es colas têm adotado êsse sistema, parece que com melhor resul tado que 0 nosso.

Por êsses motivos a Escola passou a exigir tempo integral dos alunos e o Hospital das Clínicas passou a comissionar, anualmente, um grupo de atendentes para faze rem o curso.

Em 1958 fol o curso de Auxiliar de Enferma gem reconhecido pelo Govêrno Federal *

A sobrecarga de trabalbo do corpo docente e administrativo, ocasionada pela instalaçāo do curso de pós-gra duaçāo,o único do Brasil até 1964, aliada ao fato de funcionarem, na cidade de São Paulo, 10 cursos de auxillar de enfermagem

* Decreto Federal no 43.140, de 3 de fevereiro de 1958. 
fizeram com que a Escola considerasse o fechamento do seu curso de auxilinres, o que foi feito em 1863.

A Eiscola expediu 45 certificados a alunos do sezo masculíno e 137 alunos do sexo feminino, num total de 182 certificados.

O Papel da Escola no Desenvolvimento da Dufermagem

O primeiro Regulamento da Becola mencio neva duas finalidades : former enfermeiros e colaborar as for maçāo de novas escolas e no aperfelçanmento das já existentes.

No segundo Regulamento estas finnlidades fo ram amplindas para incluir "O desenvolvimento da enfermagem em geral".

Fiel a estas finalidades a Fscola de Enfer magem tem procurado cooperar com os Poderes Públicos e en tidades públicas e particulares em tudo quanto diz respeito a enfermagem.

Por intermédio de suas duas diretoras e do seu corpo docente cooperou na criação das escolas do Recife e de Pôrto Alegre e no desenvolvimento do currículo de escolas de enfermagem do Brastl e do estrangeiro.

Contando com o rico campo de pritica que é - Centro Médico da Universidade de Sāo Pavlo tem podido auxi liar escolas dêste e de outros países, cujos estudantea aqui vêm completar seus estágios. Assim, já ofereceu fuleçāo em Enfermagem em Centro Cirúrgico, em Doenças Transmíssiveis, na Poliomielite, Enfermagem Neurológica, Paiquiátricn, Obsté trica, Pediátrica, Ortopédica, U-ológica, Otorrinolaringolób̆ ca, Oftalmológica, Dermatológica e em Administração. Entre 
as entidades que se utllisaram desans filiaçoes figurem esco las da Argentina, Paraguat, Bahia, Minas Gerais, Rio de Janeiro, Rio Grande do Sul, Golás e interior de São Paulo.

Profeseốras e instrutoras têm ministrado a nualmente a disciplina Elemeatos de Enfermagem para os alu nos do Instituto de Reabilitaçāo, da cadeira de Ortopedia da Fa culdade de Medicina da USP. Têm ministrado aulas sobre esteri lizaçāo, enfermagem no lar, higiene mental, elementos de enfer magem etc. a estudantes de medicina, diretores de Grupo Es colar, professores primários,professores secundários, alunos de cursos médios, seminaristas e outros grupos.

Por solicitação da Secretaria da Saúde e Assistência Social, a Escola tem participado no combate a epide mias, na capital e no Interior do Estado; docentes a alunos insta laram hospitais de isolamento e neles mantiveram o serviço de enfermagem nas seguintes epidemias: meningite cérebro-espi nhal em Casa Branca, Tambaú e Fazenda Amálla, 1948; conjunt1 vite epidêmica na Casa da Criança do Juizado de Menores em São Paulo, 1951; poliomilite em Araçatuba e Bilac, 1952; molés tia julgada transmissível e mais tarde diagnosticada como rea ção alérgica em Bauru, 1952; febre tifóide em Itátiba, 1954; fé bre tifólde em Igaraçu do Tletê, 1967 .Nesta última manteve inclú sive serviço de educaçāo sanitária e prestaçāo de cuidados de enfermagem em domicllio a aproximadamente 400 familias.

Realizou 22 exames de licenciamento de Prá tico de Enfermagem, aOs quais submeteram-se 1.086 candidatos.

A. pedido da Divisão de Difusāo Cultural da Universidade de São Paulo tem ministrado cursos de extensão universitária sobre enfermagem ou matérla correlata.Ainda em 1967 realizou curso sobre Higlene Mental, para o qual houve mais de 400 matrículas.

Tem cooperado intensa e constantemente com a Associaçāo Brasileira de Enfermagem, em tôdas as suas atividades culturais, assistenciais ou de divulgaçāo. No seu prédio foi realizado o 19 Congresso Brasilleiro de Enfermagem, 
em 1847, promovido pela primeira diretora da Escola, entr̃o presidente daquela Associação. Em 1953 a Escola hospedou as delegadas do Conselho Internacional de Enfermeiras e nas suas salas procesenram-se as reuntöes do Conselbo de Delega das, que precederam o X Congreaso Internacional de Enferma gem, realizado em Petrópolis. Anualmente suas profeseôras e instratoras ministram grande parte dos cursos oferecidos a enfermeiras, auxiliares de enfermagem ou a outros grupos, tais como 08 cursos de Enfermagem no Lar, que säo realizados duas vêzes ao ano. Suas salas estr̈o sempre abertas para êstes cur sos bem como para bazares e festas daquela Associação.

Membros da Escola têm cooperado com o Ministério da Educação e Cultura fazendo verificação de esco las de enfermagem e de auxiliar de enfermagem, para efeito de autorizaçāo de funcionamento ou reconhecimento. A atual dire tora e uma de suas instrutoras participaram da Comissão de Especialistas no Ensino de Enfermagem, no último govêrno.

Membros do corpo docente atuaram como consultoras na reorganização do Hospital Ernesto Dornelles,em Pôrto Alegre e do Centro Cirúrgico do Primeiro Hospital Dis trital de Brasúlia.

O corpo discente tem trabalhado voluntària mente em diversas obras sociais tais como dispensários particula res em bairros pobres, MUD, campanhas de alfabetizaçāo, cam panhas de erradiçaçāo de doenças, etc. Como o número de cann didatas ao curso de graduação é limitado, em virtude de pré conceito social contra a enfermeira, preconceito ésse nascido do desconhecimento generalizado sobre o papel dessa profissio nal, o corpo discente, por sua própria iniciativa,tem feito cam panhas de esclarecimento do públicado, em sāo Paulo e no in terior. 


\section{Conclusāo}

No decorrer de sua existência, tem a Escola procurado preencher suas finelldades, nāo só formando enfer meiros e obstetrizes e oferecendo-lhes oportunidade de aperfei çoamento, como cooperando com os Poderes Públicos e entida des públicas e particulares no desenvolvimento da enfermagem.

Tendo começado em 1943, com um curso, rea 112a agora sete : dois de graduaçāo, quatro pós-graduaçāo e um de complementaçāo.

Inicialmente anexa ì F'aculdade de Medicina é hoje estabelecimento de ensino superior.

Graças ao trabalho do seu corpo docente, ao campo de prática de que dispōe e à dedicaçāo de seus funcioná rios a Escola de Enfermagem da Universidade de Säo Paulo, se guindo as linhas traçadas por sua fundadora, projetou-se no ce nário da enfermagem brasileira.

PINHEIRO, M.R. S. - Histórico da Escola de Enfermagem da USP. Revista da Escola de En fermagem da USP, 1 (1): $3-34$, out. 1967. 